\section{Hearing loss and dementia}

Iliffe and Manthorpe's editorial in the August issue ${ }^{1}$ is apposite in view of the publication in July of the Lancet Commissions' report Dementia prevention, intervention, and care, which expands on several of the themes raised. ${ }^{2}$ In particular, the editorial's focus on the role of general practice in prevention and research is to be welcomed. However they do not mention hearing loss, to which the Lancet report devotes considerable space and ascribes a significant potential preventive role. Hearing loss is independently associated with developing dementia in about one-third of cases.

Recent research has suggested that use of hearing aids may reduce or prevent the increased prevalence of dementia seen in adults with hearing loss. ${ }^{3,4}$ This needs confirmation, as current evidence is weak due to the large number of confounding factors. General practice is ideally suited to carry out this research thanks to our largescale and long-duration databases. In the meanwhile, GPs are likely to see increasing numbers of patients asking for referral for hearing aids, as some in the commercial sector are stating this benefit of hearing aids as fact. Such referral should be expedited; GPs are sometimes accused of minimising hearing loss and delaying referral, but early users of hearing aids are more likely to use aids successfully over a longer timescale as they can be difficult to use. Hearing loss is associated with depression and social isolation; ${ }^{5}$ denial of the disability is common, as is irritability and interference with relationships. By the age of 70 years, $70 \%$ of GP patients have hearing loss. If in doubt, or if the patient is reluctant, a simple validated screening test is available over the phone or online. ${ }^{6}$

\section{Ted Leverton,}

Retired GP, RCGP Clinical Advisor.

E-mail: TLevertondaol.com

\section{Competing interests}

Ted Leverton has hearing loss and undertakes training sessions on hearing loss for health professionals. He is a volunteer at Action on Hearing Loss.

\section{REFERENCES}

1. lliffe S, Manthorpe J. Dementia: is the biopsychosocial model vindicated? Br J Gen Pract 2017; DOI: https://doi.org/10.3399/bjgp17X691781.

2. Lancet Commissions. Dementia prevention, intervention, and care. 2017. http://mww.thelancet. com/pdfs/journals/lancet/PIIS0140-6736(17)31363-6. pdf laccessed 5 Sep 2017).

3. Amieva H, Ouvrard C, Giulioli C, et al. Self-reported hearing loss, hearing aids, and cognitive decline in elderly adults: a 25-year study. J Am Geriatr Soc 2015; 63(10): 2099-2104.

4. Lin FR, Yaffe K, Xia J, et al. Hearing loss and cognitive decline in older adults. JAMA Intern Med 2013; 173(4): 293-299.

5. Dawes P. Emsley R, Cruickshanks KJ, et al. Hearing loss and cognition: the role of hearing aids, social isolation and depression. PLoS One 2015; 10(3): e0119616. http://www.ncbi.nlm.nih.gov/pmc/articles/ PMC4356542/ (accessed 5 Sep 2017).

6. Action on Hearing Loss. Check your hearing. https:// uww.actiononhearingloss.org.uk/your-hearing/ look-after-your-hearing/check-your-hearing/takethe-check.aspx laccessed 5 Sep 2017).

DOI: https://doi.org/10.3399/bjgp17X692669

\section{Adrenaline auto- injector prescribing may be putting patients at risk}

Adrenaline auto-injector (AAll) prescribing for children in UK primary care has increased dramatically since 2000.' As these young patients grow older, an increasing number of adults will require AAls to mitigate their risk of an anaphylactic reaction.

Current National Institute for Health and Care Excellence (NICE) guidance advises that adults and children aged $>12$ years should receive $500 \mu \mathrm{g}$ adrenaline intramuscularly at the onset of suspected anaphylaxis, with doses of $300 \mu \mathrm{g}$ and $150 \mu \mathrm{g}$ advised for children aged $6-12$ years and $<6$ years respectively. ${ }^{2}$

Arecent audit of AAl prescribing I undertook while working at a West London surgery found $100 \%$ adherence to these doses for patients aged $<6$ years, but adherence fell to $62 \%$ in children aged $6-12$ years and to just $3 \%$ in patients aged $>12$ years.

The current lack of a $500 \mu \mathrm{g} \mathrm{AAl}$ in the popular 'EpiPen' range may be a factor in the underdosing of adults at risk of anaphylaxis
$196 \%$ of AAls prescribed were from this range). Five-hundred microgram AAls are available as part of the local formulary at a similar price to 'EpiPen' products but appear to be seldom prescribed despite this.

Care should also be taken to ensure that the dose of AAl prescribed is increased appropriately as young patients turn 6 and 12 to avoid the potential for undertreatment of life-threatening anaphylactic reactions.

Duncan Baily,

Foundation Year 2 Doctor, North West Thames Foundation School.

E-mail: duncan.bailyladoctors.org.uk

\section{REFERENCES}

1. Diwakar L, Cummins $C$, Ryan $R$, et al. Prescription rates of adrenaline auto-injectors for children in UK general practice: a retrospective cohort study. Br J Gen Pract 2017; DOI: https://doi.org/10.3399/ bjgp17X689917.

2. National Institute for Health and Care Excellence. Anaphylaxis: assessment to confirm an anaphylactic episode and the decision to refer after emergency treatment for a suspected anaphylactic episode. London: NICE, 2011

DOI: https://doi.org/10.3399/bjgp17X692957

\section{Bad Medicine: The medical untouchables}

As a named petitioner in the Scottish Parliament public petition cited by Des Spence in this article, ${ }^{1}$ I would like to thank Dr Spence wholeheartedly for his support on $T V$ and radio, and now in this journal. I would also like to thank the BJGP for publication. We too have been 'banging on about this', (the harm caused by prescription drugs) on behalf of patients, for years. We have become acutely aware of how 'untouchable' the topic is for doctors, and aware of their extreme discomfort when patients try to flag up the issues. GPs, especially, seem to have been placed in an extraordinarily difficult situation altogether by a system that has failed to provide them with the guidance and support that they surely deserve. Perhaps, between us all, we can truly recognise what has gone wrong and start to really communicate collaboratively about what needs to happen now. 